\title{
Peripheral Neuropathy and "Borderline" Diabetes
}

\author{
Neil R. Holland, MB, BS, and Calin I. Prodan, MD
}

There is a clear association between sensory polyneuropathy and overt diabetes mellitus. The incidence of neuropathy increases with duration of diabetes; ultimately, up to $50 \%$ of patients are affected. ${ }^{1,2}$ Improved glycemic control has been shown to prevent and delay progression of diabetic neuropathy, ${ }^{3}$ emphasizing the importance of early diagnosis and aggressive management in these patients. There is increasing evidence that patients with milder degrees of abnormal glucose metabolism, including impaired glucose tolerance (IGT) and impaired fasting glucose (formerly referred to as "borderline" diabetes), are also at risk for developing symptomatic polyneuropathy (Tables 1 and 2). ${ }^{4,5}$ We have personally observed patients for several years with "idiopathic" painful sensory neuropathy who subsequently develop overt diabetes; in retrospect, it seems likely that their symptoms were related to longstanding impaired glucose metabolism. This interesting association calls for further investigation with prospective studies.

\section{Case Reports}

\section{case 1}

This 67-year-old woman presented with a 3-year history of numbness and burning pain in her feet. Initially, she noticed numbness in the toes associated with burning pain and paresthesias. With time, these symptoms slowly intensified, and progressed to involve her legs to the knees and into the fingertips. She also complained of nocturnal leg pain, cramping, and restlessness. Her examination showed diminished sensitivity to pinprick and heat pain over both feet up to the knee and the distal fingertips. Vibratory sensitivity was mildly reduced at the great toe but normal at the ankle. The ankle jerks were present. Electrodiagnostic testing was

Submitted, revised, 30 July 2003.

From West Long Branch, New Jersey (NRH) and the Department of Neurology, University of Oklahoma Medical Center, Oklahoma City (CIP). Address correspondence to Dr. Neil R. Holland, 107 Monmouth Road, West Long Branch, NJ 07764 (e-mail: nhollan@dnamail.com).
Table 1. Classification of Abnormal Glucose Metabolism Based on the 2-Hour Oral Glucose Tolerance Test, Which Consists of Fasting Blood Glucose Level and Blood Glucose Level Measured 2 Hours after a 75-g Oral Glucose Load ${ }^{4}$

\begin{tabular}{lccc}
\hline Diagnosis & $\begin{array}{c}\text { Fasting } \\
\text { Glucose } \\
(\mathrm{mg} / \mathrm{dL})\end{array}$ & and & $\begin{array}{c}\text { 2-Hour Post } \\
\text { Load Glucose } \\
(\mathrm{mg} / \mathrm{dL})\end{array}$ \\
\hline $\begin{array}{c}\text { Normal glucose } \\
\text { metabolism }\end{array}$ & $<110$ & and & $<140$ \\
$\begin{array}{c}\text { Impaired fasting } \\
\text { glucose }\end{array}$ & $110-125$ & and & $140-199$ \\
$\begin{array}{c}\text { Impaired glucose } \\
\text { tolerance }\end{array}$ & $<126$ & or & $\geq 200$ \\
\begin{tabular}{c} 
Diabetes mellitus \\
\hline
\end{tabular} & $\geq 126$ & &
\end{tabular}

normal. Blood work, including fasting glucose, glycohemoglobin, and vitamin $\mathrm{B}_{12}$ levels and serum protein electrophoresis, was normal. She did not undergo an oral glucose tolerance test (OGTT). She was diagnosed with idiopathic small-fiber neuropathy. Her symptoms were treated first with nortriptyline and then with gabapentin. Her pain continued to progress, and over the course of the next year, she was also taking tramadol, replaced within another year by oxycodone. One year later, 5 years after the onset of her initial complaints, she had a vitreous hemorrhage and was found to have proliferative retinopathy. She underwent a 2-hour OGTT. The fasting glucose was normal at $99 \mathrm{mg} /$ $\mathrm{dL}$, but the 2-hour glucose was elevated at 228 $\mathrm{mg} / \mathrm{dL}$, satisfying diagnostic criteria for diabetes, and she was started on metformin. She continued to take low-dose oxycodone and gabapentin but her neuropathic symptoms stabilized.

Table 2. Age-Adjusted Prevalence of Neuropathy in Patients with Altered Glucose Metabolism Compared with That of Control Subjects 5

\begin{tabular}{lr}
\hline Normal Glucose Metabolism & $3.9 \%$ \\
Impaired Glucose Tolerance & $11.2 \%$ \\
Diabetes Mellitus & $25.8 \%$ \\
\hline
\end{tabular}




\section{Case 2}

This 65-year-old obese woman had a history of chronic low back pain. Magentic resonance imaging of the lumbar spine had shown multilevel degenerative changes, and she had been treated with intermittent facet and epidural steroid injections. She presented with a 6-year history of burning pain and numbness affecting the soles of both feet that was unresponsive to these treatments. Her examination showed reduced sensitivity to pinprick, temperature and pain affecting both feet up to the level of the ankles. Vibratory sensitivity, strength and reflexes were normal. Electrodiagnostic testing was normal. Skin biopsy showed epidermal denervation. Blood work, including fasting glucose, glycohemoglobin, and vitamin $\mathrm{B}_{12}$ levels, syphilis serology, and serum protein electrophoresis, was normal. She subsequently underwent a 2-hour OGTT, which showed a normal fasting glucose of $101 \mathrm{mg} / \mathrm{dL}$ but elevated 2-hour glucose at 188 $\mathrm{mg} / \mathrm{dL}$, indicating impaired glucose tolerance. She was started on a diabetic diet, exercise program, and gabapentin. When re-evaluated 3 months later, her symptoms were improved, and her OGTT was now normal (2-hour glucose, $108 \mathrm{mg} / \mathrm{dL}$ ).

\section{Case 3}

This 54 year-old man presented with an 18-month history of multiple mononeuropathies. He first developed right-sided foot drop, followed by right hand numbness and weakness, and then weakness at the left ankle. An extensive battery of blood work was performed at the referring facility, including fasting glucose, vitamin $B_{12}$ level, syphilis serology and serum protein electrophoresis and glycohemoglobin; results of all tests were normal. He did not undergo an OGTT at that time. Lumbar puncture showed elevated protein at $122 \mathrm{mg} / \mathrm{dL}$ (reference range, 15 to $45 \mathrm{mg} / \mathrm{dL}$ ) and white blood cell count of $3 / \mathrm{mm}^{3}$ (reference range, $0-5 / \mathrm{mm}^{3}$ ). These results were interpreted as albuminocytologic dissociation supportive of a diagnosis of chronic inflammatory demyelinating neuropathy, and he was placed on $60 \mathrm{mg} /$ day oral prednisone for 1 month. Nevertheless, his condition continued to worsen, and he noted increasing burning pain and paresthesias as well as erectile dysfunction. On examination, he had mild right-sided ptosis with mild weakness of right medial rectus and an enlarged right pupil. There was mild wasting of the right thigh and calf, with mild symmetric distal weakness, aside from the right ankle, which was disproportionately weak. He had patchy areas of sensory loss, including the right shoulder, left forearm, and right lateral calf. Reflexes were absent. Electrodiagnostic testing showed asymmetric motor and sensory axonal loss. Magnetic resonance imaging and angiography of the brain, performed for the suspicion of vasculitis, were normal. Repeat lumbar puncture showed only the same albuminocytologic dissociation. He ultimately underwent a nerve and muscle biopsy, which showed reduced densities of large and small nerve fibers and denervation atrophy. There was no histologic evidence of inflammation or vasculitis. He was started on gabapentin and sildenafil, and tapered off the prednisone. He was reevaluated for diabetes during the discontinuation of the prednisone, and glycohemoglobin was found to be elevated at $6.4 \%$ (reference value, $\leq 5.7 \%$ ). He was believed to have developed steroid-induced diabetes. Three months after discontinuing the prednisone, his glycohemoglobin was back within the normal range (5.6\%), but a 2-hour OGTT showed a borderline normal fasting glucose at 108 $\mathrm{mg} / \mathrm{dL}$, and a 2-hour glucose that was elevated at $180 \mathrm{mg} / \mathrm{dL}$, consistent with impaired glucose tolerance. Three months after starting a diabetic diet, his OGTT was within normal limits (fasting glucose, $102 \mathrm{mg} / \mathrm{dL}$; 2-hour glucose, $123 \mathrm{mg} / \mathrm{dL}$ ), and his neurologic deficits had stabilized. The initial presentation was consistent with mononeuropathy multiplex, including partial third nerve palsy. $\mathrm{He}$ went on to develop a painful polyneuropathy. $\mathrm{He}$ was ultimately found to have impaired glucose tolerance, perhaps exacerbated by steroids. Both mononeuropathy multiplex and albuminocytologic dissociation are seen with diabetes, and in retrospect, impaired glucose metabolism may have been the cause of his symptoms all along.

\section{Discussion}

The cause of polyneuropathy remains unknown in more than $20 \%$ of cases despite extensive laboratory testing. ${ }^{6}$ The incidence of idiopathic cases is believed to be even higher among patients presenting with painful sensory neuropathy. ${ }^{7,8}$ However, some patients with "idiopathic" painful sensory neuropathy have ultimately developed overt diabetes mellitus after many years of follow-up, suggesting that occult impairment of glucose metabolism may have been the cause of their symptoms all 
Table 3. The Incidence of Occult Diabetes and Impaired Glucose Tolerance in Patients Referred to Neuromuscular Clinics with a Diagnosis of 'Idiopathic' Sensory Neuropathy

\begin{tabular}{ll}
\hline Study & \multicolumn{1}{c}{$\begin{array}{c}\text { Incidence of Impaired } \\
\text { Glucose Metabolism }\end{array}$} \\
\hline Palade et al, 2000 & $10 / 75(13 \%)$ \\
Singleton et al, 2001 & $48 / 107(45 \%)^{*}$ 13 DM and 35 IGT \\
Novella et al, 2001 & $24 / 48(50 \%)+11 \mathrm{DM}$ and 13 IGT \\
Sumner et al, 2003 & $41 / 73(56 \%)$ 15 DM and 26 IGT \\
\hline
\end{tabular}

DM, diabetes mellitus; IGT, impaired glucose tolerance; GTT, oral glucose tolerance test.

* Includes 13 of 33 patients with abnormal GTT and normal fasting glucose, and 10 of 21 patients with abnormal GTT and normal glycosylated hemoglobin level.

† Of the 28 patients with painful neuropathy, 18 (65\%) had abnormal glucose metabolism ( 8 of 28 DM and 10 of 28 IGT).

along. ${ }^{9}$ There have been a number of recent series suggesting than more than $50 \%$ of the patients referred to neuromuscular clinics with a diagnosis of "idiopathic" painful sensory neuropathy have abnormal glucose metabolism when they are evaluated using the 2-hour glucose tolerance test (Table 3). ${ }^{10-13}$ Of these, more than $50 \%$ have impaired glucose tolerance, so the fasting glucose and glycohemoglobin are frequently normal despite an abnormal glucose tolerance test. ${ }^{11}$ These incidences of occult diabetes and impaired glucose tolerance are significantly higher than those reported for the general population, suggesting a causal relationship. ${ }^{11,14}$

Diabetic polyneuropathy is typically a distal symmetric sensorimotor process that involves both small- and large-caliber fibers. Clinically, sensory symptoms are very common, and in many cases, the neuropathy is painful because of prominent small fiber involvement. ${ }^{15}$ Skin biopsy for epidermal nerve fiber quantification has been useful for evaluating painful diabetic neuropathy and shows epidermal denervation in these cases. ${ }^{16-19}$ A number of recent studies have also shown epidermal denervation in patients with impaired glucose tolerance and painful sensory neuropathy. ${ }^{20,21}$ These patients have lesser degrees of epidermal denervation and are more likely to have normal nerve conduction studies than those with diabetic neuropathy, ${ }^{11,13,20}$ consistent with the hypothesis that neuropathy from impaired glucose tolerance may be a precursor to diabetic neuropathy with more selective small fiber involvement. Furthermore, many newly diagnosed diabetic patients already have clinical and electrophysiologic evidence of neuropathy, ${ }^{22,23}$ suggesting that lesser degrees of hyperglycemia may be associated with the onset of nerve fiber degeneration.

Although there is increasing evidence that impaired glucose tolerance may cause a painful sensory neuropathy indistinguishable from mild diabetic neuropathy, there have not yet been any prospective studies investigating the value of improved glycemic control in these patients. However, it is known that patients with impaired glucose tolerance are at increased risk for the development of overt diabetes and that this risk can be reduced by weight loss, exercise, and initiation of oral hypoglycemic agents. ${ }^{24,25}$ Furthermore, it also known that improved glycemic control can prevent and delay progression of diabetic neuropathy. ${ }^{3}$

\section{Conclusion}

Based on the data available in the current medical literature, we suggest that patients presenting with unexplained painful sensory neuropathy should be evaluated for impaired glucose metabolism with a 2-hour OGTT; if the results of the test are abnormal, they should be referred for lifestyle interventions and/or initiation of oral hypoglycemic agents in addition to management of neuropathy symptoms. Improved glycemic control can prevent the development of overt diabetes mellitus and may have some impact on progression of neuropathy in these cases. The association between "idiopathic" painful sensory neuropathy and impaired glucose metabolism argues very strongly for prospective studies in larger populations looking at the costeffectiveness of this approach.

\section{References}

1. Dyck PJ, Kratz KM, Karnes JL, et al. The prevalence by staged severity of various types of diabetic neuropathy, retinopathy, and nephropathy in a population-based cohort: the Rochester Diabetic Neuropathy Study [published erratum appears in Neurology 1993;43:2345]. Neurology 1993;43:817-24.

2. Cohen JA, Jeffers BW, Faldut D, Marcoux M, Schrier RW. Risks for sensorimotor peripheral neuropathy and autonomic neuropathy in non-insulindependent diabetes mellitus (NIDDM). Muscle Nerve 1998;21:72-80.

3. Anonymous. The effect of intensive treatment of diabetes on the development and progression of 
long-term complications in insulin-dependent diabetes mellitus. The Diabetes Control and Complications Trial Research Group. N Engl J Med 1993; 329:977-86.

4. Anonymous. Report of the Expert Committee on the Diagnosis and Classification of Diabetes Mellitus. Diabetes Care 1997;20:1183-97.

5. Franklin GM, Kahn LB, Baxter J, Marshall JA, Hamman RF. Sensory neuropathy in non-insulindependent diabetes mellitus. The San Luis Valley diabetes study. Am J Epidemiol 1990;131:633-43.

6. Dyck PJ, Oviatt KF, Lambert EH. Intensive evaluation of referred unclassified neuropathies yields improved diagnosis. Ann Neurol 1981;10:222-6.

7. Holland NR, Crawford TO, Hauer P, Cornblath DR, Griffin JW, McArthur JC. Small-fiber sensory neuropathies: clinical course and neuropathology of idiopathic cases. Ann Neurol 1998;44:47-59.

8. Periquet MI, Novak V, Collins MP, et al. Painful sensory neuropathy: prospective evaluation using skin biopsy. Neurology 1999;53:1641-7.

9. Holland NR. Idiopathic painful sensory neuropathy. J Clin Neuromusc Dis 2001;2:211-20.

10. Palade A, Small GA. Diabetes mellitus is underdiagnosed in patients with sensory peripheral neuropathy [abstract]. Muscle Nerve 2000;23:1632-3.

11. Singleton JR, Smith AG, Bromberg MB. Painful sensory polyneuropathy associated with impaired glucose tolerance. Muscle Nerve 2001;24:1225-8.

12. Novella S, Inzucchi SE, Goldstein JM. The frequency of undiagnosed diabetes and impaired glucose tolerance in patients with idiopathic sensory neuropathy. Muscle Nerve 2001;24:1229-31.

13. Sumner CJ, Sheth S, Griffin JW, Cornblath DR, Polydefkis $M$. The spectrum of neuropathy in diabetes and impaired glucose tolerance. Neurology 2003;1460:108-11.

14. Harris MI, Flegal KM, Cowie CC et al. Prevalence of diabetes, impaired fasting glucose, and impaired glucose tolerance in US adults. The Third National
Health and Nutrition Survey, 1988-1994. Diabetes Care 1998;21:518-24.

15. Said G, Slama G, Selva J. Progressive centripetal degeneration of axons in small fibre diabetic neuropathy. Brain 1993;106:791-807.

16. Brown MJ, Martin JR, Asbury AK. Painful diabetic neuropathy: a morphometric study. Arch Neurol 1976;33:164-171.

17. Levy DM, Karanth SS, Spingall DR, Polak JM. Depletion of cutaneous nerves and neuropeptides in diabetes mellitus: an immunocytochemical study. Diabetologica 1989;32:427-33.

18. Kennedy WR, Wendelschafer-Crabb G, Johnson T. Quantification of epidermal nerves in diabetic neuropathy. Neurology 1996;47:1042-8.

19. Holland NR, Stocks A, Hauer P, Cornblath DR, Griffin JW, McArthur JC. Intraepidermal nerve fiber density in patients with painful sensory neuropathy. Neurology 1997;48:708-11.

20. Smith AG, Ramachandran P, Tripp S, Singleton JR. Epidermal nerve innervation in impaired glucose tolerance and diabetes-associated neuropathy. Neurology 2001;57:1701-4.

21. Sheth S, Sumner C, Hauer P, et al. The spectrum of small fiber nerve involvement in IGT and diabetes [abstract]. Neurology 2002;58(Suppl 3):A165.

22. Ratzmann KP, Raschke M, Gander I, Schimke E. Prevalence of peripheral and autonomic neuropathy in newly diagnosed type II (noninsulin-dependent) diabetes. J Diabet Complications 1991;5:1-5.

23. Lehtinen JM, Uusitupa M, Siitonen O, Pyorala K. Prevalence of neuropathy in newly diagnosed NIDDM and nondiabetic control subjects. Diabetes 1989;38:1307-13.

24. Tuomilehto J, Lindstrom J, Eriksson JG et al. Prevention of type 2 diabetes mellitus by changes in lifestyle among subjects with impaired glucose tolerance. N Engl J Med 2001;344:1343-50.

25. Knowler WC, Barrett-Connor E, Fowler SE, et al. Reduction in the incidence of type 2 diabetes with lifestyle intervention or metformin. $\mathrm{N}$ Engl J Med 2002;346:393-403. 